\title{
Gorza, Anabella y Valobra, Adriana (Editoras). (2018) Género y derechos. Una propuesta para el aula de Ciencias Sociales - 1a ed. - La Plata: Universidad Nacional de La Plata. Facultad de Humanidades y Ciencias de la Educación, 171 páginas.
}

\author{
Santiago Lamboglia \\ Facultad de Humanidades y Ciencias de la Educación/ \\ Universidad Nacional de La Plata, Argentina \\ santiago.lamboglia@gmail.com
}

El Cuadernillo Género y Derechos: una propuesta transformadora para el aula de Ciencias Sociales tiene como interés principal reconstruir y sistematizar un conjunto de procesos históricos a partir de una perspectiva de género de los sujetos. Para ello, como sostienen sus editoras, Anabella Gorza y Adriana Valobra, quienes participaron de su redacción escriben desde una concepción feminista de la pedagogía, a través de la cual proponen la escucha y la enseñanza como partes constitutivas de un proceso educativo.

Uno de los puntos más interesantes del libro es su anclaje en una praxis política, pedagógica y académica, tanto con relación al proceso a partir del cual se llega a su redacción final, como al objetivo y al público al que está dirigido. En cuanto al primer aspecto, es interesante notar que la elaboración del cuadernillo es parte de una experiencia que se dio en el marco de un proyecto de extensión de la Universidad Nacional de La Plata (UNLP). Este incluyó no sólo la escritura del libro, sino que implicó también la puesta en práctica de las secuencias didácticas incluidas allí en dos colegios secundarios pertenecientes a la UNLP y en un taller de educación informal.

Todas estas experiencias resultaron fundamentales para la elaboración de las propuestas didácticas, ya que a partir de ello éstas fueron revisadas, reescritas y luego de ello sistematizadas en la versión definitiva del libro. En cuanto al segundo aspecto, que hace referencia al público al que pretende interpelar el libro y a los objetivos que persigue, nos parece interesante remarcar que el interés principal del cuadernillo gira en torno a la sistematización de recursos áulicos que permitan interpretar y enseñar las ciencias sociales desde una perspectiva de género. Se parte del punto de que, pese a que los/as docentes elaboraron y elaboran constantemente estrategias para introducir la perspectiva de género en sus clases, no ha existido una traducción sistematizada de aquellas iniciativas a través materiales para la enseñanza en el aula, algo que se profundiza aún más entre las editoriales especialistas en bibliografía escolar. En este sentido, la elaboración del cuadernillo pretende dar una respuesta a ese vacío editorial, sistematizando y promoviendo la utilización de recursos didácticos que incluyan la perspectiva de género en las clases de ciencias sociales. De esta manera, tanto el interés que persigue el libro como la forma a la que se llega a su producción final combinan un interés y una producción teórica que se encuentra directamente vinculada y condicionada por la práctica, en una proceso que Paulo Freire (1970) denomina praxis, es decir, la capacidad de producir conocimiento teórico partiendo y teniendo como perspectiva la práctica política y pedagógica.

En el primer capítulo, escrito por Gorza y Valobra, las editoras se concentran en desarrollar una definición de perspectiva de género. Remarcan la importancia de pensar, enseñar y aprender las Ciencias Sociales desde la perspectiva genérica, concibiéndola tanto como una herramienta para interpretar y revisar procesos poniendo el foco sobre aspectos que de otra manera pasarían inadvertidos-, como también una perspectiva que permite dar voz a sujetos/as y grupos sociales dejados de lado por las interpretaciones historiográficas 
tradicionales. A su vez, según las historiadoras, la propuesta de analizar desde una perspectiva de género a las ciencias sociales no significa observar únicamente las cuestiones vinculadas a las mujeres o lo "femenino", ya que de esa manera implicaría pensar a los varones o identidades disidentes no binarias como sujetos carentes de género.

En ese sentido, a lo largo del cuadernillo nos encontramos con un abordaje histórico que no se limita sólo a una historia de las mujeres, sino que se analizan aspectos relacionados, por ejemplo, al impacto de las políticas estatales en la configuración de las ciudadanías basadas en concepciones genéricas binarias, a las respuestas que suscitaron dichas políticas en los colectivos de mujeres y más recientemente en la comunidad trans, o al impacto que tuvieron esas políticas en la configuración de modelos de masculinidad determinadas.

El contenido específico del cuadernillo, en el que se abordan las propuestas didácticas, comienza en el capítulo dos y se extiende hasta el capitulo seis. El segundo capítulo, escrito por las historiadoras María Cristina Garriga y Viviana Pappier, funciona como una suerte de presentación de la secuencia didáctica en la que se explica el esquema general de los capítulos restantes, fundamentalmente vinculada a aspectos didácticos. Allí, las autoras realizan una crítica al formato tradicional de clase en la que el/la docente realiza preguntas a partir de su exposición, en un acto que, según ellas, no habilita necesariamente la intervención de los/as estudiantes. Como alternativa, las historiadoras proponen el formato de taller, en donde todo el proceso pedagógico aparece articulado a partir de la pregunta del/la docente, buscando de esa manera generar interés, reflexión y apropiación de los temas que se aborden entre los/as estudiantes.

Los siguientes capítulos son los que concentran las propuestas didácticas del cuadernillo, y aparecen divididos entre sí por temas: cada uno de ellos aborda un derecho en particular y, a su vez, todos se subdividen en dos partes: en una primera se hace un abordaje historiográfico de cada tema y, en una segunda parte, se desarrollan las secuencias didácticas propuestas en cada capítulo. Los derechos que se abordan son: Derechos Civiles (matrimonio y género); Derechos Sexuales (luchas por el reconocimiento de la identidad de género); Derechos Politicos (contrato social/contrato sexual) y Derechos Sociales (trabajo y género).

El abordaje histórico que se hace en cada capítulo está intrínsecamente relacionado con el desarrollo y la dinámica del Estado-nación en Argentina. Se analizan principalmente el impacto de leyes y políticas impulsadas por el Estado y las respuestas que generaron entre distintos sectores sociales. Temporalmente, se abordan los últimos años del siglo XIX hasta el presente, lo que limita el uso del cuadernillo como material didáctico a las materias de ciencias sociales que aborden temáticas vinculadas a problemáticas sociales del estado argentino durante el período mencionado. Cada capítulo es analizado desde una perspectiva de género, lo que hace que el cuadernillo sea un material sumamente interesante para ser utilizado en las aulas escolares, en donde escasean este tipo de materiales y abundan las obras permeadas de interpretaciones históricas tradicionales. Es a partir de ello que el cuadernillo habilita, por ejemplo, la posibilidad de abordar algunos temas a partir del concepto de "contrato sexual" (Pateman, 1988). Entre ellos se encuentran la ley Sáenz Peña y su vinculación con los derechos políticos; la división sexual del trabajo en el marco de los derechos sociales; y el matrimonio como un proceso de institucionalización de la desigualdad entre varones y mujeres en cuanto a los derechos civiles.

Por otra parte, en la secuencia didáctica que ofrece el cuadernillo, nos encontramos con un conjunto amplio de fuentes históricas que incluyen historietas, leyes, decretos, revistas, biografías, fotografías, panfletos y documentos de organizaciones y partidos políticos y literatura, tanto cuentos como fragmentos de libros. Uno de los aspectos más valiosos del cuadernillo es la variedad de recursos que ofrece -tanto en cuanto a dinámicas de trabajo para el aula como fuentes documentales- y la flexibilidad que propone y que habilita a los/as docentes que quieran utilizarlo a modificar, seleccionar, recortar o ampliar las actividades y las metodologías propuestas, de manera tal que pueda ser incluido armónicamente a diversas secuencias didácticas en proceso.

Pese a esta variedad, escasean con relación al resto, las fuentes documentales que visibilicen las problemáticas de género que atravesaron a los sectores populares. Como ha señalado el historiador Jim Sharpe 
(1993), generalmente existen numerosas limitaciones existentes para el uso directo de fuentes pertenecientes a las clases bajas. En ese sentido, la perspectiva de género propuesta en las actividades didácticas del cuadernillo se vería enriquecida por la posibilidad de introducir la variable de clase en el trabajo del aula.

Visto en su conjunto, el cuadernillo sin lugar a dudas cumple con el objetivo de proponer una lectura histórica y secuencias didácticas que privilegian una perspectiva de género. Por último, no quisiéramos dejar de señalar que las propuestas didácticas son lo suficientemente abiertas como para permitir modificaciones y adaptaciones posibles y la riqueza de las fuentes documentales incluidas hacen que el cuadernillo sea un material sumamente valioso para el trabajo en el aula. Es de lectura ágil y, sin dudas, aportará a todo aquel/lla docente que busque herramientas para abordar y profundizar la historia desde una perspectiva de género.

\section{BibLIOgRAFÍA}

Freire, P. (1970). Pedagogía del oprimido. Montevideo: Tierra nueva.

Pateman, C. (1988). The Sexual contract. Oxford: Cambridge Polity Press.

Sharpe, J.(1993). Historia desde abajo. En Burke, P. (ed.). Formas de hacer Historia, pp. 38-58. Madrid: Alianza Editorial. 